\title{
In vivo evaluation of cp Ti implants with modified surfaces by laser beam with and without hydroxyapatite chemical deposition and without and with thermal treatment: topographic characterization and histomorphometric analysis in rabbits
}

\author{
Thallita Pereira Queiroz ${ }^{1}$ Rafael Scaf de Molon ${ }^{2}$ - Francisley Ávila Souza ${ }^{3}$. \\ Rogério Margonar ${ }^{1}$ Anahi Herrera Aparecida Thomazini ${ }^{4}$. \\ Antônio Carlos Guastaldi ${ }^{4}$ - Eduardo Hochuli-Vieira ${ }^{2}$
}

Received: 21 January 2016 / Accepted: 5 August 2016 /Published online: 16 August 2016

(C) Springer-Verlag Berlin Heidelberg 2016

\begin{abstract}
Objective We aimed to assess the surfaces of commercially pure titanium implants (cp Ti) with modified surfaces by laser beam (LS) with and without hydroxyapatite (HA) deposition, without (HAB) and with (HABT) thermal treatment. Furthermore, we have compared them with implants with surfaces modified by acid treatment (AS) and with machined surfaces (MS) utilizing histomorphometric and descriptive histologic analyses.

Material and methods Surface topography characterization was analyzed by scanning electron microscopy (SEM), Xray energy-dispersive spectroscopy (EDX), and surface roughness $(\mathrm{Ra})$ before implant installation. Forty-five rabbits received seventy-five implants in their left and right tibias and were randomly divided into five groups $(n=5$ implants per
\end{abstract}

Thallita Pereira Queiroz and Rafael Scaf de Molon contributed equally to this work.

Thallita Pereira Queiroz

thaqueiroz@hotmail.com

Rafael Scaf de Molon

molon.foar@yahoo.com.br

1 Department of Health Sciences, Implantology Post Graduation Course, Dental School, University Center of Araraquara (UNIARA), Avenida Jose Bonifacio, 128, Araraquara, SP 14801-150, Brazil

2 Department of Diagnosis and Surgery, School of Dentistry at Araraquara, Sao Paulo State University (UNESP), Rua Humaitá 1680, Araraquara, SP 14801-903, Brazil

3 Department of Surgery, School of Dentistry at Araçatuba, Sao Paulo State University (UNESP), Araçatuba, SP, Brazil

4 Biomaterials Group, Physical-Chemistry Department, Chemistry Institute of Araraquara, Sao Paulo State University (UNESP), Araraquara, SP, Brazil group): (1) cp Ti implant modified by LS, (2) cp Ti implant modified by laser beam associated with HA deposition without heat treatment (HAB), (3) cp Ti implant modified by laser beam associated with HA deposition with heat treatment (HABT), (4) cp Ti implant with modified surface by means of acid treatment (Master Porous) commercially available (AS), and (5) cp Ti implant with MS commercially available. After 30, 60, and 90 days, the animals were euthanized and the implants and surrounding bone were removed and prepared by a non-decalcified histological process. The percentage of bone-to-implant contact (BIC) and the bone area fraction occupancy (BAFO) between the first three threads was evaluated to the higher cortical region.

Results BIC (\%) was statistically superior $(p<0.001)$ on the LS $(69.36 \pm 7.91,71.67 \pm 8.79$, and $79.69 \pm 3.3)$, HAB $(73.22 \pm 3.75,69.48 \pm 1.89$, and $75.7 \pm 4.62)$, and HABT $(65.41 \pm 5.51,71.3 \pm 2.5$, and $79.68 \pm 5.01)$ compared with AS (49.15 $\pm 5.76,41.94 \pm 2.85$, and $57.18 \pm 7.81)$ and MS (36.69 $\pm 7.24,52.52 \pm 2.75$, and $51.31 \pm 6.96)$ in the 30,60 , and 90 -day periods, respectively. BAFO (\%) of HAB at 30 days $(90.17 \pm 6.24)$ was statistically superior $(p<0.01)$ to all the other groups. At 60 and 90 days, BAFO of LS $(87.17 \pm 5.9$ and $87.99 \pm 2.52), \mathrm{HAB}(85.95 \pm 3.93$ and $82.17 \pm 3.65)$, and HABT $(83.27 \pm 1.44$ and $88.67 \pm 2.67)$ was higher than the AS (77.49 \pm 5.83 and $76.42 \pm 5.98)$ and MS (74.01 \pm 4.68 and $73.81 \pm 4.91)$.

Conclusions Collectively, our data indicate that the modified surfaces LS, HAB, and HABT favored the interaction between bone and implant and increased bone formation. In addition, HAB showed higher biological behavior favoring the osseointegration.

Clinical relevance Our study provides evidence that LS, $\mathrm{HAB}$, and HABT-modified surfaces improved bone-to- 
implant contact and increased bone formation around osseointegrated implants compared to conventional machined implants favoring the osseointegration process.

Keywords Dental implantation · Histomorphometric analysis $\cdot$ Surface properties $\cdot$ Laser $\cdot$ Hydroxyapatite

\section{Introduction}

Dental implants' surface properties play an important role as one of the six most significant factors for implant incorporation in the bone tissue. The establishment of osseointegration is dependent of the six following parameters, accordingly to Albrektsson et al. [1]: (1) implant material, (2) implant design, (3) implant finish (surface), (4) status of the bone, (5) surgical technique, and (6) implant loading conditions. Implants of commercially pure titanium (cp Ti) stand out as a reliable material to rehabilitate edentulous areas of the jaws; however, they require a long period for osseointegration, and the success rate is dependent on the quality of the bone tissue [2]. The development of implant surfaces has been proposed to promote bone-to-implant contact and accelerate bone repair in this interface, allowing immediate or early loading of the implant especially in patients with significant systemic alterations that impair adequate bone healing and in cases of severe atrophy of the jaws [3-5].

Topographic properties and physicochemical surface of the implants are essential in the early stages of osseointegration, as they are responsible for the biological responses of biomaterials [6-12]. Accelerated bone formation and bone resistance can provide better implant stability during the bone healing process allowing faster implant placement and prosthetic rehabilitation [13]. In this context, different methods for implant surface modifications have been proposed, including techniques that remove material particles (subtraction process), such as acid etching (sulfuric acid followed by hydrochloric acid), acid treatment (sulfuric acid $\left(\mathrm{H}_{2} \mathrm{So}_{4}\right)$, hydrofluoric acid (HF), nitric acid $\left(\mathrm{HNO}_{3}\right)$, and hydrochloric acid (HCL)) with aluminum oxide particles $\left(\mathrm{Al}_{2} \mathrm{O}_{3}\right)$ or titanium oxide $\left(\mathrm{TiO}_{2}\right)$ [14] with or without sandblasting, anodic oxidation [15], and laser ablation [16]. On the other hand, other techniques add material to the implant surface (addition process), such as coatings with HA and calcium phosphate (Ca-P) [16, 17], titanium plasma spray (TPS), or HA plasma spray [18].

Considerable advance has been made in understating the mechanisms of protein adsorption as well as in the understanding of cell-material interface to enhance the biological response around dental implants [19-22]. The process of cell adhesion involves adsorption of proteins to the substrate, contact, and attachment of cells, followed by spreading on the substrate [21]. Surface chemical composition and surface energy are essential parameters that might have a critical influence on the interaction of biomaterial surfaces with proteins and cells and can influence which proteins are adsorbed $[19,20]$. The implant surface energy measured by the liquidsolid contact angle and thus related to wettability is another surface characteristic known to affect the biological response to the implant [23]. Surface wettability can affect four major aspects of the biological system: (1) soft and hard tissue cell interactions with the surfaces, (2) adhesion of proteins and other macromolecules onto the surface, (3) rate of osseointegration, and (4) bacterial adhesion and subsequent biofilm formation $[23,24]$. Thus, the more wettable the material is, the better the human body tolerates it [21]. The surface modification with lasers is a controllable and flexible process that can promote their wettability $[10,21]$. This process results in increased hardness, corrosion resistance, and other important surface implant properties [25]. In addition, irradiation with laser beam produces a high purity surface and roughness sufficient to favor osseointegration [26].

Another surface modification employed to accelerate implant osseointegration and favoring bone tissue interaction is surface coated with ceramic Ca-P [12, 27-30]. The Ca-P is released in the peri-implant region increasing the saturation of body fluid with consequent biological apatite precipitation on the implant surface. This layer of apatite should contain endogenous proteins acting as a matrix for integration and growth of osteogenic cells [27, 31, 32]. Previous studies [33-35] showed that the biological fixation of implants to bone is faster with Ca-P coating when compared to those without coverage so the process of bone healing around implants is accelerated by the formation of a biological apatite layer on the surface. Several methods have been developed and tested for coating implants, especially the HA plasma spray, sol-gel method, electrophoretic deposition, and biomimetic deposition [33-37]. The more disseminated HA deposition method in the literature is plasma spray, in which increases in the percentage of bone-to-implant contact compared to uncoated implants were frequently observed [38, 39]. However, this method has considerable disadvantages due to the high temperatures used in this process, which alters the HA structure and impairs the coating adhesion to the implant surface [38-40].

Recently, the biomimetic method for HA coating has been recognized for producing a homogeneous layer of bone-like apatite, which enhances the adhesion to metal substrate. This method is one of the most promising techniques for biomaterial production because it mimics the biological bone and tooth formation process via the use of a solution with composition, $\mathrm{pH}$, and temperature similar to human blood plasma, known as simulated body fluid (SBF). The biomimetic method allows practically all types of substrate, with any size and morphology, to be coated with a uniform layer of apatite and allows control over coating characteristics, such as composition, crystallinity, and thickness [41-44]. Irradiation of the 
surface by laser beam prior to the chemical deposition of apatites by biomimetic method improves the physical-chemical bond stability between the coatings and implant surface. This is due to the formation of titanium oxides at the implant surface after irradiation with laser beam and its high affinity for $\mathrm{Ca}$ and $\mathrm{P}$ present in SBF [28, 29, 45-47].

Here, continuing our studies evaluating these modified implant surfaces, in which we have previously assessed LS, $\mathrm{HAB}$, and HABT surfaces by means of biomechanical analysis [28], we aimed to evaluate the surfaces of commercially pure titanium implants (cp Ti) modified by laser beam (LS) with and without hydroxyapatite (HA) deposition by biomimetic method, without (HAB) and with heat treatment (HABT), comparing them with implants with surfaces modified by treatment with acid (AS) and with machined surface (MS) by means of histomorphometric analysis. The rational for this study is that implant surface treatment plays a major role in implant osseointegration. In this regard, our hypothesis was that implant with modified surface (LS, HAB, and HABT) would favor the osseointegration process increasing bone-to-implant contact and bone area fraction occupancy.

\section{Materials and methods}

\section{Implants}

In this study, seventy-five external hexagon implants with a diameter of $3.75 \times 10 \mathrm{~mm}$ length (Conexao Implant Systems, Aruja, Sao Paulo, SP, Brazil) and with five different surfaces were used. Three of these surfaces were test surfaces, which were modified in the Biomaterials Group of the Institute of Chemistry (Sao Paulo State University (UNESP), Araraquara, SP, Brazil), and the other two were commercially available surfaces, which constituted the control groups. The groups were described as (1) cp Ti implant modified by LS, (2) cp Ti implant modified by laser beam associated with HA deposition by means of biomimetic method, without heat treatment (HAB), (3) cp Ti implant modified by laser beam associated with HA deposition by means of biomimetic method, with heat treatment (HABT), (4) cp Ti implant with modified surface by means of acid treatment (Master Porous), commercially available (AS), and (5) cp Ti implant with MS, commercially available.

\section{Preparation of test surfaces}

\section{Surface modification by laser beam}

The cp Ti implants were fixed at the rotating device under the pulsed laser equipment $20 \mathrm{~W}$ Yb (Ytterbium Pulsed Fiber Laser System Omnimark 20F, Ominitek Tecnologia Ltda, Sao Paulo, Brazil) with the parameters of nominal power and pulse rate of $140 \mathrm{~mJ}$ and $20 \mathrm{KHz}$, respectively. The laser beam was projected onto the entire surface of the implant threads in room atmosphere, as previously described [28].

\section{Modified surface by laser beam and HA deposition using the biomimetic method}

The protocol was established following previous protocol [28]. Briefly, the samples were immersed in $50 \mathrm{~mL}$ of $\mathrm{NaOH}(5.0 \mathrm{~mol} / \mathrm{L})$ in the oven for a period of $24 \mathrm{~h}$ at $60{ }^{\circ} \mathrm{C}$ for surface activation. Then, the implants were kept in an oven for $3 \mathrm{~h}$ at $60{ }^{\circ} \mathrm{C}$ for drying the surface. The biomimetic method is a physicochemical process in which a biologically active Ca-P covering is produced on a substrate after soaking in an acellular protein-free supersaturated $\mathrm{Ca}$ and $\mathrm{P}$ SBF which replicates the human blood plasma by having ionic composition and $\mathrm{pH}$ similar to plasma $[41,48]$. Each implant was placed vertically in $20 \mathrm{~mL}$ of $\mathrm{SBF}$ and remained immersed in this solution for a period of 4 days at $37^{\circ} \mathrm{C}$ and $\mathrm{pH} 0.25$, to obtain a coating composed of HA. The ionic concentration of the solution was previously described [28]. The SBF was changed every $24 \mathrm{~h}$ to retain the amount of ions in the solution. After the HA coating procedure, half of the implants (HABT) were submitted to heat treatment. For this, implants were kept in a specific oven (EDG 3P-S 1800, EDG Equipment) for $1 \mathrm{~h}$ at $600{ }^{\circ} \mathrm{C}$. After the immersion period, the substrates were removed from the solution, washed with demineralized water, and dried at room temperature.

\section{Surface characterization}

Prior to implant installation in the rabbit tibia, the implant topography was analyzed by means of scanning electron microscopy (SEM) (MEV XL 30 TMP, FEG, Philips XL Series, Oxford detector with Inca X-sight, Holland, 97), coupled to a system of scattering spectroscopy system for energydispersive X-ray (EDX) for semi-quantitative analysis of the surface's chemical composition. In this regard, five implants of each group were used. The implants were positioned inside the SEM, and five areas from each sample were arbitrarily chosen by a blinded examiner. Images were made with both secondary and backscattered electrons. For EDS analysis, $7 \mathrm{kV}$ accelerating voltage was used to improve peak/back ground ratio for light elements.

In addition, $\mathrm{cp}$ Ti disks were modified with different surfaces as described above and examined in cross section by SEM to determine the average thickness of 10 random points on the surfaces measured in five disks per group. The average roughness $(\mathrm{Ra})$ (the arithmetic mean of the sampling area roughness, measured in $\mu \mathrm{m}$ ) of each surface was analyzed using a digital roughness meter (Mitutoyo SJ-400, MitutoyoSul Americana Ltda, Sao Paulo, Brazil) with an accuracy of $0.01 \mathrm{~mm}$, a reading length of $2.5 \mathrm{~mm}$, an active tip 
speed of $0.5 \mathrm{~mm} / \mathrm{s}$, and a radius of $5 \mu \mathrm{m}$. To verify the reliability of the results, a device was used to stabilize and standardize the analysis. The reading at two different times was assessed by a masked examiner.

Sterilization and packing of the modified implants were conducted before implant installation in the rabbit by the implant company (Conexão Implant Systems, Arujá, São Paulo, Brazil) after surface topography characterization.

\section{Sample size calculation}

For our animal experiment, sample size calculation was based on bone-to-implant contact (BIC) data of the author's pilot study (unpublished data) previous to the commencement of the studies. For this purpose, we have determined BIC as primary outcome. For this variable, we considered as significant a difference of $5 \%$ (standard deviation of $2 \%$ ), and for $80 \%$ power and setting alpha at 0.05 , five implants per group were necessary in order to compare five different groups.

\section{Animals and implants}

Rabbits and surgical procedures were handled according to the guidelines of the local Ethical Committee for Animal Care and Use (protocol \#2007-004959). We followed a randomized, prospective, controlled, animal model design following all the recommendations of the Animal Research: Reporting In Vivo Experiments (ARRIVE) guidelines for the execution and submission of studies in animals [49]. Rabbits were kept in the animal facilities with controlled temperature, humidity, and a 12-h light/dark cycle. Throughout the experimental period, rabbits were housed in individual plastic cages, fed a standard laboratory diet (Procoelho, Primor, SP, Brazil), and given water ad libitum. A total of 45 5-month-old white male rabbits (New Zealand), variation Albinus, with average body weight between 3 and $4 \mathrm{~kg}$ were randomly divided into five groups of dental implant surfaces. A total of 75 implants were installed, in which 30 animals received two implants in each tibial metaphysis, randomly (60 implants). One group of five animals in each experimental period of 30, 60, and 90 days (total of 15 animals) received only one implant. Importantly, the choice of each tibia to receive particular type of implant occurred randomly, by means of drawing lots.

\section{Implant surgery}

Experimental surgery for implant placement was performed as described [28]. The animals were fasted for $8 \mathrm{~h}$ prior to surgery, and general anesthesia was done by intramuscular (im) injection of a combination of ketamine hydrochloride (Vetaset, Fort Dodge Animal Health Ltd., Campinas, SP, Brazil) at a concentration of $50 \mathrm{mg} / \mathrm{kg}$ and xylazine hydrochloride (Dopaser, Laboratory Calier of Brazil Ltda, Osasco, SP, Brazil) at $5 \mathrm{mg} / \mathrm{kg}$. Then, rabbits were submitted to a trichotomy in both tibias after disinfection with iodine solution (10\% polyvinylpyrrolidone, Riodeine germ, Rioquimica, Sao Jose do Rio Preto, SP, Brazil). Then, the animals underwent local anesthesia by infiltrative injection with mepivacaine hydrochloride $(0.3 \mathrm{~mL} / \mathrm{kg}$, Scandicaine $2 \%$ with epinephrine 1:100,000, Septodont, France) to assist hemostasis of the wound area.

A 3-cm incision was performed on the proximal tibia just below the knee, bilaterally, and the tibial metaphysis was exposed by blunt dissection, in which complete thickness of soft tissue was dissected, exposing the bone tissue for implant placement. Then, receptor beds were prepared using a progressive sequence of drills (lance drill, spiral $2.0 \mathrm{~mm}$, pilot 2.0/3.0 mm, and 3.0-mm helical drill, Conexao Implant System, SP, Brazil), under profuse sodium chloride irrigation at 1200 RPM (Darrow, Rio de Janeiro, RJ, Brazil). Subsequently, each type of implant surface was installed in each tibia, using both cortical bones (medial and lateral tibial metaphysis). The soft tissues were replaced and sutured in separate layers, using absorbable threads (poligalactina 910, Vycril 4.0, Ethicon, Johnson Prod., Sao Jose dos Campos, SP, Brazil), and the skin was sutured with monofilament suture (Nylon 4.0, Ethicon, Johnson, Sao Jose dos Campos, SP, Brazil).

In the immediate postoperative period, the animals received a single intramuscular injection of pentabiotic $(0.1 \mathrm{~mL} / \mathrm{kg}$, Fort Dodge Animal Health Ltd., Campinas, Sao Paulo, SP Brazil) and a single dose of dipyrone sodium (1 mg/kg/day Ariston Chemical and Pharmaceutical Industries Ltda, Sao Paulo, SP, Brazil) for a total of three doses.

\section{Animal euthanization and analyses}

Fifteen rabbits were euthanized by lethal dose of intramuscular ketamine administration at 30 , at 60 , and at 90 days postoperatively. The tissue samples (bone-implant interface) in each tibia from each group were removed and fixed in $10 \%$ paraformaldehyde for $72 \mathrm{~h}$.

\section{Sample preparation and histomorphometric procedures}

Tissue samples for non-decalcified sections were dehydrated in increasing concentrations of ethanol (60-100\%) and were then embedded in light-cured resin (Technovit 7200 VLC, Heraeus Kultzer GmbH \& Co., Wehrheim, Germany). The blocks containing the implant and peri-implant bone tissue were cut at a central point, aiming the center of the implant diameter along its long axis using a cutting-grinding unit (EXAKT Apparatebeau, Hamburg, Germany). A single section was obtained from each implant. The sections were reduced to a final thickness of $30 \mu \mathrm{m}$ 
by grinding and polishing using a microgrinding unit (EXAKT Apparatebeau, Hamburg, Germany), and the sections were stained with Stevenel blue and acid fuchsin. The percentage of $\mathrm{BIC}$ and the bone area fraction occupancy (BAFO) within the threads were measured in both sides of the implants at the three first threads, according to previous studies [5, 12, 28, 39, 50, 51]. The mean values of both sides of the implant were considered.

\section{Bone histomorphometry}

The histological slides were analyzed using a light microscopy (DiaStar, Reichert \& Jung Products, Leica, Germany), and images were captured by a digital camera Leica Microsystems DFC-300-FX (Leica Microsystems, Germany) with a resolution of 1.3 megapixels, coupled to the optical microscope common light allowing computer-based histomorphometric measurements. The digital images of histological slides were imported, and the histomorphometric analysis was performed using image analysis software (IMAGELAB 2000, version 2.4) in a standardized manner by one blinded and calibrated examiner, masked to the original treatment protocol. The results of the linear extension of BIC and BAFO between the threads occupied by the bone tissue obtained from the square pixels and pixels, respectively, were converted to percentage values, as described [5]. To evaluate the bone near to the implant, two histomorphometric variables were analyzed as stated:

1. The implant linear extension including bone tissue in contact with the implant surface, between the initial three threads in the mesial and distal region (BIC);

2. Area between the threads, occupied by bone tissue in the first three implant threads in the mesial and distal region (BAFO). The values of BIC and BAFO for each group were compared with each other in three periods and for different groups at each period evaluated.

A sample of each group of 30-day period was processed again (using the other half of the block containing the implant sectioned at the midpoint), as described above. The obtained slides were not stained and were metallized to analyze the distribution and homogeneity of $\mathrm{Ca}$ and $\mathrm{P}$ (elemental mapping), using SEM, EDX, and electron microprobe attached.

\section{Statistics}

Analyses were performed using GraphPad Prism Software 5.0 (GraphPad Software, Inc., La Jolla, CA, USA). Group measures were expressed as mean \pm the standard error of the mean (SEM). The data obtained in each type of comparison were tested using the Kolmogorov-Smirnov test, which confirmed the normally distribution of all the data and analysis. Therefore, statistical significance was assessed using one-way analysis of variance (ANOVA) followed by post hoc Tukey's test for multiple comparisons among groups $(\alpha=0.025)$.

\section{Results}

\section{Surface topography characterization}

The characterization of the surface topography was evaluated by means of SEM, EDX, and Ra before implant placement in the rabbit tibia. The SEM surface analysis showed topographical differences between the groups. The LS (Fig. 1a-b), HAB (Fig. 1b-c), and HABT (Fig. 1e-f) produced rough and homogeneous surfaces with regular morphology as well as the presence of spherical particles suggesting nanoscale structures. Analysis by EDX showed no contamination on the implant surfaces and showed peaks of titanium (Ti) and oxygen (O) for LS. The EDX of HAB and HABT maintained the characteristics of the LS, differing just by the presence of peaks corresponding to the calcium $(\mathrm{Ca})$ and phosphorus $(\mathrm{P})$ elements obtained by chemical deposition of $\mathrm{Ca}-\mathrm{P}$.

The AS implant surface showed a pattern of subtraction topography and formation of micro cavities of different depths and sizes, however, maintaining a homogeneous roughness (Fig. 1g-h). The EDX of AS showed peaks of Ti and O, and MS showed peaks of Ti (Fig. 1i-j).

Cross-sectional representative images of LS (Fig. 2a), HAB (Fig. 2b), HABT (Fig. 2c), and AS (Fig. 2d) acquired by means of SEM shows the average thickness of the different surfaces, which where LS (21.76 $\pm 9.05 \mu \mathrm{m})$, HAB $(44.21 \pm 6.63 \mu \mathrm{m})$, HABT $(35.31 \pm 9.77 \mu \mathrm{m})$, and AS $(7.84 \pm 3.73 \mu \mathrm{m})$. The MEV cross section in the HAB and HABT showed the presence of a "hybrid" layer formed by laser beam irradiation followed by the deposition of HA, not allowing to distinguish the two surface treatments alone.

The microtopographic analysis revealed statistically significant difference $(p<0.05)$ between the HAB and HABT roughness (6.61 \pm 0.84 and $6.35 \pm 0.7 \mu \mathrm{m}$, respectively) compared to $\operatorname{LS}(\mathrm{Ra}=4.73 \pm 0.48 \mu \mathrm{m}), \operatorname{AS}(\mathrm{Ra}=1.34 \pm 0.35 \mu \mathrm{m})$, and MS $(0.4 \pm 0.06 \mu \mathrm{m})$ and LS compared to AS and MS (Fig. 3).

\section{Histomorphometric analysis}

The effect of surface modification on implant integration in the rabbit tibia was accessed by histomorphometric analysis. $\mathrm{BIC}$ of the $\mathrm{LS}(69.36 \pm 7.91,71.67 \pm 8.79$, and $79.69 \pm 3.3)$, $\mathrm{HAB}(73.22 \pm 3.75,69.48 \pm 1.89,75.7 \pm 4.62)$, and HABT $(65.41 \pm 5.51,71.3 \pm 2.5,79.68 \pm 5.01)$ implants was statistically superior $(p<0.001)$ when compared to the AS $(49.15 \pm 5.76,41.94 \pm 2.85,57.18 \pm 7.81)$ and $\mathrm{MS}$ $(36.69 \pm 7.24,52.52 \pm 2.75,51.31 \pm 6.96)$ implants in the 
Fig. 1 SEM $(500 \times)$ and EDX for all the surfaces studied: $\mathbf{a}-\mathbf{b} \mathrm{LS}$, c-d HAB, e-f HABT, g-h SA, and $\mathbf{i}-\mathbf{j}$ MS

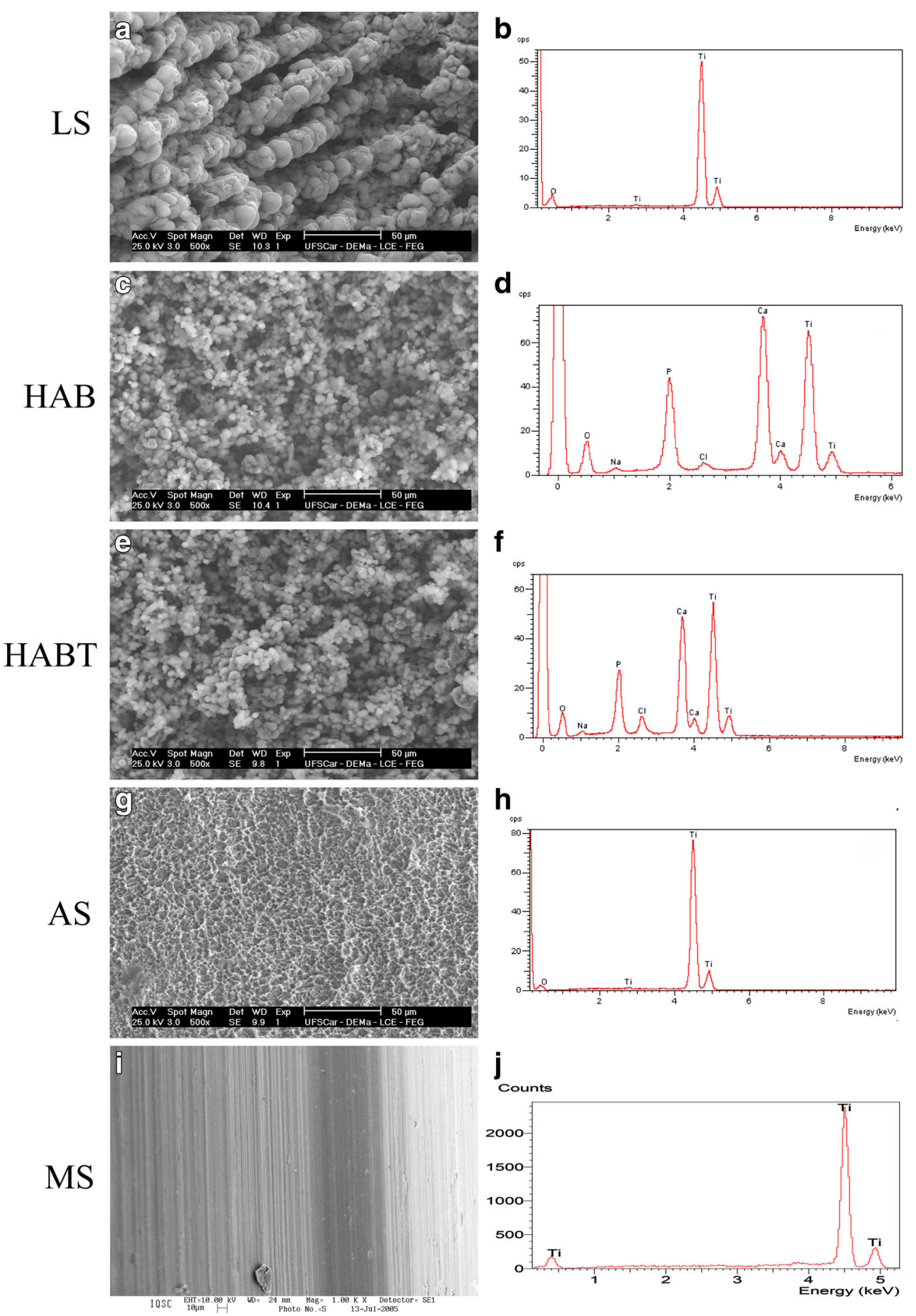

three periods evaluated, respectively. At 30 and 90 days, AS was statistically higher than MS $(p<0.05)$ (Fig. 4).

The BAFO analysis of HAB at 30 days $(90.17 \pm 6.24)$ was statistically superior to all the other groups $(p<0.01)$. During this period, BAFO of the LS and AS showed statistically significant difference when compared to MS $(p<0.01$ and $p<0.001$, respectively). At 60 and 90 days, BAFO of LS $(87.17 \pm 5.9,87.99 \pm 2.52), \operatorname{HAB}(85.95 \pm 3.93$, $82.17 \pm 3.65)$, and HABT $(83.27 \pm 1.44,88.67 \pm 2.67)$ was superior to the AS $(77.49 \pm 5.83,76.42 \pm 5.98)$ and MS $(74.01 \pm 4.68,73.81 \pm 4.91)(p<0.01)$ (Fig. 5).

\section{Descriptive histologic analysis}

Descriptive histologic analysis at 30 days showed new bone formation between the threads of the LS, HAB, and HABT implants, in the cortical region presenting a regular and more homogeneous collagen fiber with concentric lamellae 
Fig. 2 SEM of surfaces (crosssection images) for aLS, $\mathbf{b} \mathrm{HAB}$, c HABT, and d AS $(1000 \times)$
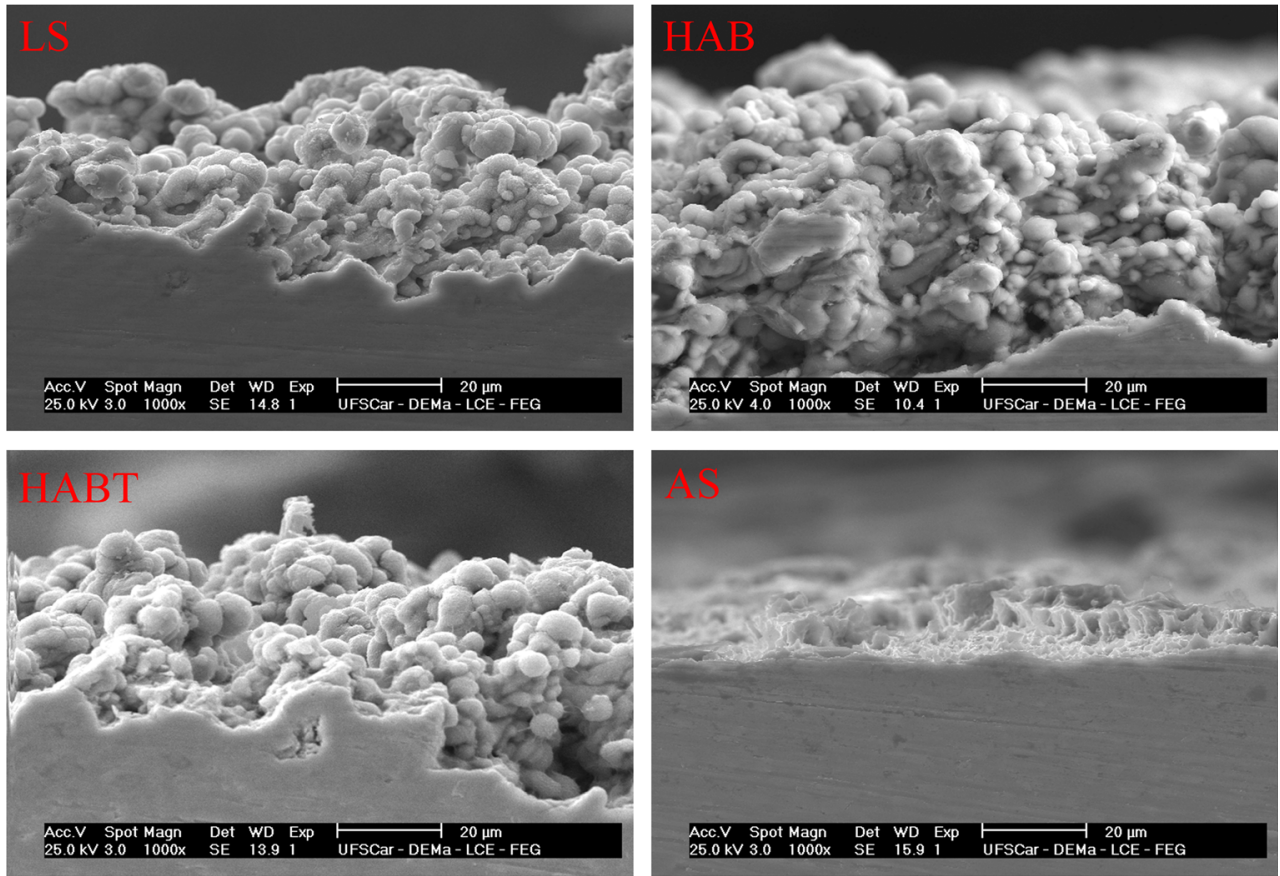

demonstrating continuing tissue remodeling, maturation, and formation. Moreover, there was a significant interface contact established between these surfaces and the bone tissue (Fig. 6a). Small areas of immature tissue (stained with Stevenel blue) with the presence of osteoblasts arranged in palisade could be observed, suggesting that they are in the process of bone matrix synthesis (Fig. 6a, white arrows). $\mathrm{HAB}$ at 30 days showed greater contact interface with the bone tissue but did not provide statistically significant higher bone formation between the threads $(p<0.01)$ when compared to all the other groups.

In the periods of 60 and 90 days for LS, HAB, and HABT, there are increased tissue maturation and maintenance of

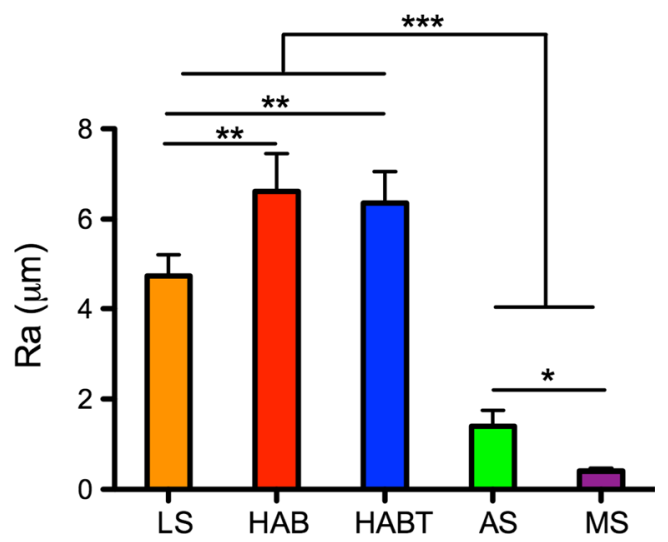

Fig. 3 Average of roughness in all the surfaces studied. * $p<0.05$, statistically significant difference from indicated groups. $* * p<0.001$, statistically significant difference from indicated groups. $* * * p<0.0001$, statistically significant difference from indicated groups. Differences among groups were calculated by one-way ANOVA. Data represent the mean \pm SEM significant contact interface between the surfaces and the bone tissue (Fig. 6b, c).

For AS and MS groups at 30 days, there are reduced amount of trabecular bone between the implant threads in the cortical region, associated with immature connective tissue (stained with Stevenel blue). Moreover, the collagen fibers are arranged with less organized and less mature tissue (Fig. 6a). In some regions, there is clear separation between pre-existing bone and newly formed bone (Fig. 6a, yellow arrows).

At 60 and 90 days, the bone pattern of AS and MS is more mature with larger surface contact interface with the bone tissue, although it is possible to note some areas of immature connective tissue between the bone trabeculae (Fig. 6b, c) and

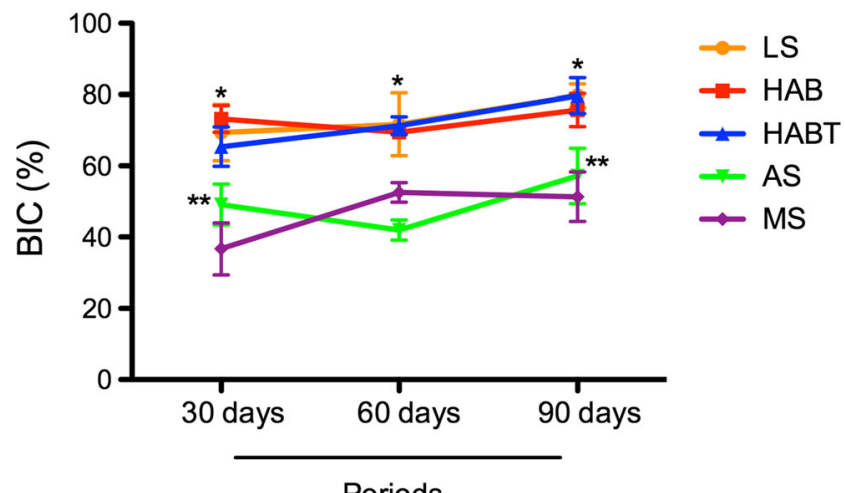

Fig. 4 BIC in all surfaces and periods evaluated. * $p<0.001$, LS, HAB, and HABT were statistically significantly different from AS and MS in the three periods evaluated. $* * p<0.05$, AS was statistically significantly different from MS at 30 and 90 days. Differences among groups were calculated by one-way ANOVA. Data represent the mean \pm SEM 


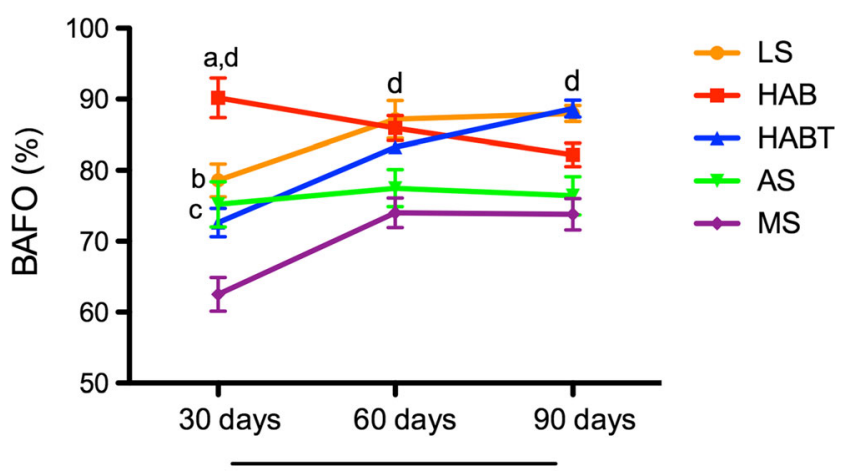

Periods

Fig. 5 BAFO in all surfaces and periods evaluated. HAB was statistically significantly different from all the others in the three periods evaluated, $p<0.01(a)$. LS $(b)$ and AS (c) was statistically significantly different from MS at 30 and 90 days, $p<0.01$ and $p<0.001$, respectively. LS, $\mathrm{HAB}$, and $\mathrm{HABT}$ were statistically significantly different from all the others at 60 and 90 days $(d)$. Differences among groups were calculated by one-way ANOVA. Data represent the mean \pm SEM

the presence of pre-existing bone without tissue remodeling in some regions (Fig. 6c, green asterisk).

When comparing each group with each other at different periods, it was found that BAFO and BIC of the MS group differed significantly in the periods of 30 to 60 days and 30 and 60 to 90 days. The BIC of the HABT differed significantly from the 30 and 60 to 90 days, and BAFO differed among all periods. For AS, the difference was only observed in BIC comparing the periods of 60 and 90 days, and for the LS group, the difference was only observed in BAFO among the different periods (Tables 1 and 2).

\section{Elemental mapping}

The EDX was used for the analysis of the homogeneity and distribution of $\mathrm{Ca}$ and $\mathrm{P}$ in all the surfaces studied. The results showed high peaks of $\mathrm{Ca}$ and $\mathrm{P}$ in all the different surfaces utilized: LS (Fig. 7a-b), HAB (Fig. 7c-d), HABT (Fig. 7e-f), AS (Fig. 7g-h), and MS (Fig. 7i-j). Highlighting the colors blue for $\mathrm{Ti}$, green for $\mathrm{Ca}$, and red for $\mathrm{P}$, Figure $7 \mathrm{a}, \mathrm{c}, \mathrm{e}, \mathrm{g}, \mathrm{i}$ is a superimposition of the images of the different elements for each surface group.

\section{Discussion}

The machined implants are stabilized in the bone tissue through the bone growth in small irregularities in its surface characterizing a biomechanical union. Therefore, for implants with small roughness, the interaction with the bone tissue is time-dependent, which is a negative aspect of these surfaces $[13,52,53]$. Thus, modifications of the implant surfaces play an important role to promote faster osseointegration allowing earlier implant rehabilitation, especially in cases of limited bone availability and in patients with compromised general health or any condition known to modify bone metabolism that would affect the healing process. Modifications to increase the speed of osseointegration have included the use of HA coating, surface-free energy (SFE), and surface roughness [54].

Current evidence showed that the failure of dental implant does occur and fall broadly into two categories: early failures (failure to achieve osseointegration) and late failure (failure to maintain the osseointegration) [54]. The long-term clinical efficacy of titanium implants is influenced by periimplantitis (late failure), an inflammatory response resulting in loss of supporting bone and implant failure caused by a range of bacteria species including Porphyromonas gingivalis, Prevotella intermedia, Aggregatibacter actinomycetemocomitans, Fusobacterium nucleatum, and Bacteroides spp., affecting up to $14 \%$ of implants after 5 years [55-58]. In this regard, implant surface roughness has been considered a risk factor for peri-implantitis [59]. Bacterial adhesion to implant surfaces has previously been associated to factors such as SFE, chemical composition, and material surface irregularities and roughness by enhancing microbial retention within surface irregularities [54]. Existing study indicate that low SFE materials, with reduced surface roughness, limits plaque accumulation in vivo [60]. Indeed, surface roughness smaller than $0.2 \mu \mathrm{m}$ (nanoroughness) has been associated with lack of microbial adherence because of the larger size of most bacteria. On the other hand, Ra up to $10 \mu \mathrm{m}$ (macroroughness) would favor the bacteria adherence to the implant surface [61]. However, a previous work [62] demonstrated that there was no inflammatory response in the periimplant tissues surrounding HA-coated cp Ti implants even after 14 years of follow-up.

The procedure for implant surface treatment with laser beam was previously described by some authors $[4,16,46]$, in which they observed better bone anchorage and higher values of reverse torque for implant removal when compared to machined implants. Previous study [16] demonstrated by means of removal torque tests the effects of surface treatment created by laser ablation (Nd:YAG) followed by the deposition of HA by a chemical process, comparing them with laser ablation surface and machined surface implants installed in 48 rabbits. After 4, 8, and 12 weeks of repair, the results evidenced that HA implants reduced the period of repair and increased the bone/implant interface during the first 2 months after implant placement. Indeed, previous study [28] recently made by our group evaluated cp Ti implants with LS, HAB, and HABT surfaces and compared them with AS and MS surfaces using biomechanical analysis. This study has demonstrated that LS, HAB, and HABT implants presented physicochemical and topographical properties superior to those of AS and MS favoring the osseointegration process. The LS, $\mathrm{HAB}$, and HABT-modified surfaces favored the integration 


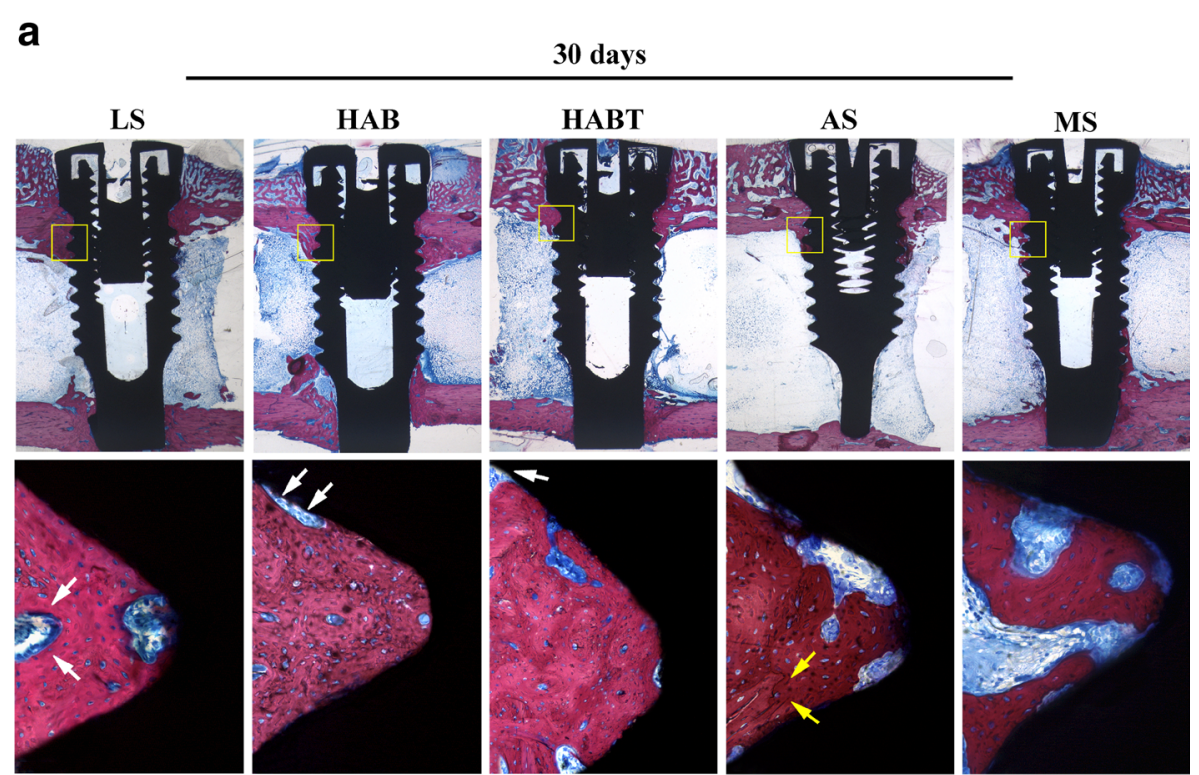

b

60 days

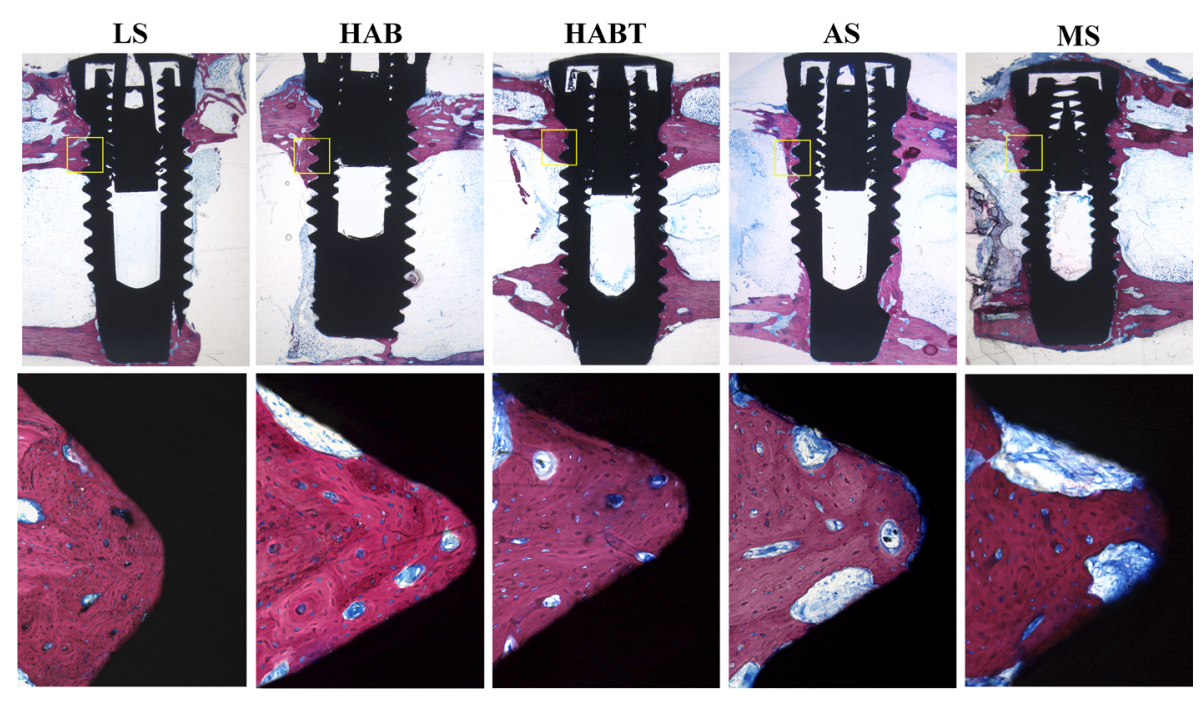

C

90 days
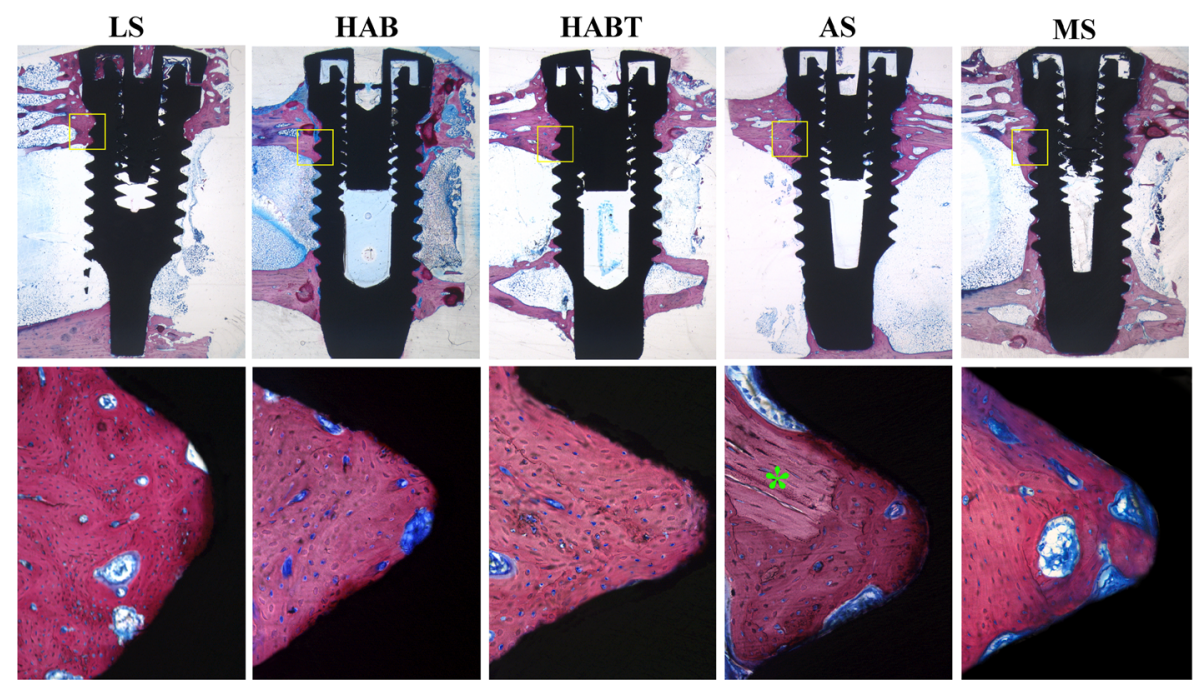
Fig. 6 Histological sections of non-decalcified sections showing the whole implant and the magnified upper cortical region (Stevenel blue and acid fuchsin, $10 \times$ and $200 \times$ magnification, respectively). a LS, HAB, HABT, AS, and MS at 30 days; b LS, HAB, HABT, AS, and MS at 60 days; c LS, HAB, HABT, AS, and MS at 90 days. Yellow squares represent the specific magnified area. White arrows point to bone matrix synthesis. Yellow arrows point to the separation between pre-existing bone and newly formed bone. Green asterisk points to pre-existing bone without tissue remodeling

between bone tissue and implant in shorter periods (30 and 60 days), accelerating osseointegration. For LS, HAB, and HABT, the rupture promoted by the biomechanical test occurred at the bone/bone interface. Indeed, HAB presented better biomechanical results when compared to the other surfaces. These results parallel observations made in our study, in which LS, HAB, and HABT implant surface demonstrated more percentage of bone-to-implant contact as well as bone area fraction occupancy compared to AS and MS surface in all periods evaluated favoring the osseointegration process, as showed in Tables 1 and 2.

In vivo and in vitro studies have demonstrated that HA enhances bone healing and improves osteoconductivity at the gaps between the implant and bone surface [63, 64]. Because HA is biocompatible and can bond with bone, it has been used to coating dental implant surfaces [65]. Although HA-coated implants integrate to the bone faster than machined implants, there are some problems associated with coating process, such as the formation of thick coating layer, coating delamination, and cohesive and adhesive failures, allied to porosity of the coating layer [66], which may be partially dissolved/reabsorbed after long periods without functioning [67]. To minimize that, we used the previous surface irradiation with laser in room atmosphere to promote chemical bonding between HA coating and the implant surface [29, 30, $47,68]$. This radiation process increase the temperature of the titanium implant surface until its fusion followed by rapid cooling resulting in the formation of a mixture of stoichiometric and non-stoichiometric titanium oxides. The oxides formed on the surface favor the chemical reaction of the HA coating with the implant resulting in standard roughness microstructure and thick $\mathrm{TiO}_{2}$ layer [69]. This process enhances the bioactivity and osteoconductivity of the Ti substrate improving the bonding strength between the HA layer and Ti substrate as well as the prevention of the corrosion of the Ti substrate. This rough surface coated by the HA layer may act by encouraging bone ingrowth into its porous structure, enhancing the mechanical fixation to the bone $[16,70]$. The deposition of HA on the surface previously modified by laser beam did not present statistical difference in relation to the percentage of $\mathrm{BIC}$ and BAFO compared to the LS surface. However, all the treated surfaces presented increased percentage of BIC and BAFO (except HABT at 30 days) compared to the AS and MS surfaces at 30,60, and 90 days, demonstrating that all treatments employed were successful in accelerating osseointegration (Tables 1 and 2).

The morphology of LS, HAB, and HABT showed no significant differences between them. All the treated surfaces presented with regular and homogeneous pattern and spherical structures at the nanoscale, which favored the deposition of bone tissue when compared to the AS and MS surfaces. However, the roughness of HAB and HABT differed significantly from the other surfaces, including LS. Although the increased roughness for HAB and HABT was noted compared to all the other groups, surface roughness did not influence the level of contact between the implant surface and bone tissue because the percentage of BIC and BAFO was not significant among treated surfaces. Furthermore, the analysis by SEM/ EDX showed the presence of $\mathrm{Ca}$ and $\mathrm{P}$ on the implant surface in HAB and HABT. In this context, our previous published paper [28] has evaluated the contact angle in all the modified surfaces to characterize its wettability. The wettability analysis involves the measurement of contact angles as the primary outcome, which indicates the degree of wetting when a solid and liquid interact. The results demonstrated that LS, HAB, and HABT surfaces did present adequate wetting in all the periods evaluated compared to AS and MS surface due to the low contact angle found in these modified surfaces.

A recent systematic review [71] evaluating the effect of surface topography on osseointegration of titanium implants
Table 1 Mean and SD of BIC (\%) of LS, HAB, HABT, AS, and MS

\begin{tabular}{|c|c|c|c|c|c|}
\hline \multirow[t]{2}{*}{ Period (days) } & \multicolumn{5}{|l|}{ Groups } \\
\hline & LS & HAB & HABT & AS & MS \\
\hline 30 & $69.36 \pm 7.91$ & $73.22 \pm 3.75$ & $65.41 \pm 5.51^{\#}$ & $49.15 \pm 5.76$ & $36.69 \pm 7.24 * * *$ \\
\hline 60 & $71.67 \pm 8.79$ & $69.48 \pm 1.89$ & $71.30 \pm 2.50 *$ & $41.94 \pm 2.85^{* *}$ & $52.52 \pm 2.75$ \\
\hline 90 & $79.69 \pm 3.30$ & $75.70 \pm 4.62$ & $79.68 \pm 5.01$ & $57.18 \pm 7.81$ & $51.31 \pm 6.96$ \\
\hline
\end{tabular}

Comparison of the values obtained for each group at 30, 60, and 90 days

$* p<0.05$, statistically significantly different compared to HABT from 60 and 90 days; $* * p<0.01$, statistically significantly different compared to AS from 90 days; $* * * p<0.01$, statistically significantly different compared to MS from 60 and 90 days; ${ }^{\#} p<0.001$, statistically significantly different 0.001 compared to HABT 90 days 
Table 2 Mean and SD of BAFO $(\%)$ of LS, HAB, HABT, AS, and MS

\begin{tabular}{|c|c|c|c|c|c|}
\hline \multirow[t]{2}{*}{ Period (days) } & \multicolumn{5}{|l|}{ Groups } \\
\hline & LS & HAB & HABT & AS & MS \\
\hline 30 & $78.59 \pm 5.19^{* * *}$ & $90.17 \pm 6.24^{*}$ & $72.65 \pm 4.44^{\#}$ & $75.21 \pm 7.17$ & $62.52 \pm 5.30^{\# \#}$ \\
\hline 60 & $87.17 \pm 5.90$ & $85.95 \pm 3.93$ & $83.27 \pm 1.44^{* *}$ & $77.49 \pm 5.83$ & $74.01 \pm 4.68$ \\
\hline 90 & $87.99 \pm 2.52$ & $82.17 \pm 3.65$ & $88.67 \pm 2.67$ & $76.42 \pm 5.98$ & $73.81 \pm 4.91$ \\
\hline
\end{tabular}

Comparison of the values obtained for each group at 30, 60, and 90 days

$* p<0.01$, statistically significantly different compared to all the other groups at 30 days; $* * p<0.05$, statistically significantly different compared to HABT from 60 and 90 days; ***p $<0.05$, statistically significantly different compared to LS from 60 and 90 days; ${ }^{\#} p<0.01$, statistically significantly different compared to MS from 60 and 90 days; ${ }^{\# \#} p<0.001$, statistically significantly different compared to HABT from 60 and 90 days showed that in numerous studies, a positive correlation has been found between surface roughness and osseointegration, and the greatest roughness was found for the implants coated with $\mathrm{Ca}$ and $\mathrm{P}$. Cooper [72] demonstrated that an increase in the surface roughness of $\mathrm{cp}$ Ti implants improved bone integration related to the amount of bone formed at the interface, increased osteoconduction, and osteogenesis. Le Guehennec et al. [73] showed in their review that surface roughness did enhance osseointegration and bone formation although the exact role of chemistry and topography is still poorly understood. The combination of blasting and etching procedure achieves an optimal roughness for mechanical fixation leading to smooth surfaces with potential importance for protein adhesion, considered to be important for the early bone healing process [71]. However, the mechanisms behind an optimal bone response to surface roughness remain largely unknown. These results close resemble our findings where significant differences for roughness of HAB and HABT were found when compared with all the other surfaces and the LS when compared to AS and MS.

Some authors $[37,71]$ have reported that whether a particular method of surface modification have the goal of changing the macroroughness, microroughness, and nanoroughness, changes in chemical surface also occur, making it difficult to identify the main factor responsible for the results when we compare implants with different surface treatments. Accordingly, previous study made by Meirelles et al. [74] compared electropolished implants (to remove the effects of the microstructure of the implants) with implants modified by coating with nanoparticles of HA in the rabbit tibia. The authors found after 4 weeks increased bone-to-implant contact for the HA-coated group. They concluded that early bone formation was dependent on the properties of HA nanoparticles. However, the authors did not show if these results were due to an isolated chemical effect or if was related to the nanotopography or a combination of both. These results are consistent to those obtained in this study, which showed a greater bone integration in the initial period of 30 days for
LS, HAB, and HABT, owing to the different physicochemical properties, and morphology with nanoscale structures.

Our results related to the percentage of BAFO indicate that HAB surface presented with a higher percentage of bone area within 30 days and greater contact interface with the bone tissue during this period, although there was no statistically significant difference among treated surfaces. This early bone integration of $\mathrm{HAB}$ is related to different physicochemical properties of HA coatings especially its bioactivity, the formation of carbonated HA similar to bone mineral, the dissolution reaction of bioceramic material, and the presence of high concentrations of $\mathrm{Ca}$ and $\mathrm{P}$. This formed HA layer can serve as a matrix for insertion and growth of the osteogenic cells [32].

The heat treatment employed over the implant surfaces after the deposition of HA has the purpose of eliminating water, increasing their crystallinity with consequent reduction of the solubility, thus increasing the stability of the deposited layer $[75,76]$. In the absence of heat treatment, the crystallinity of HA is lower, the solubility increases, and it becomes therefore more similar to biological HA. Moreover, at lower temperatures, there is a reduction of the phosphate degradation enhancing the bioactivity of the HA [67]. Indeed, our previous study [28] did address the structure and crystallinity of all the modified implant surfaces studied, which were measured by means of X-ray diffractometer (XDR). This approach has determined the crystal phase of Ca-P deposited in the implant surfaces as well as types and phases of the oxides formed. The results indicated that HAB presented lower crystallinity due to widened peaks of carbonated HA. HABT was characterized by a greater crystallinity in consequence of the heat treatment leading to a more acute and well-defined carbonated HA. Thus, we found that the formation of apatite precursors of HA, which have higher biological activity due to the absence of heat treatment [41], is related to better results in bone formation founded in the HAB group, demonstrated by the increased percentage of BIC and BAFO.

Animal research in addition to clinical research on humans has contributed greatly to the better understanding of 
Fig. 7 Element mapping analysis showing the image superimposition of the $\mathrm{Ca}$ (green), $\mathrm{P}$ (red), and Ti (blue) in all the surfaces analyzed: a-b SL, $\mathbf{c}-\mathbf{d}$ $\mathrm{HAB}, \mathbf{e}-\mathbf{f} \mathrm{HABT}, \mathbf{g}-\mathbf{h} \mathrm{AS}$, and $\mathbf{i}-\mathbf{j}$ MS
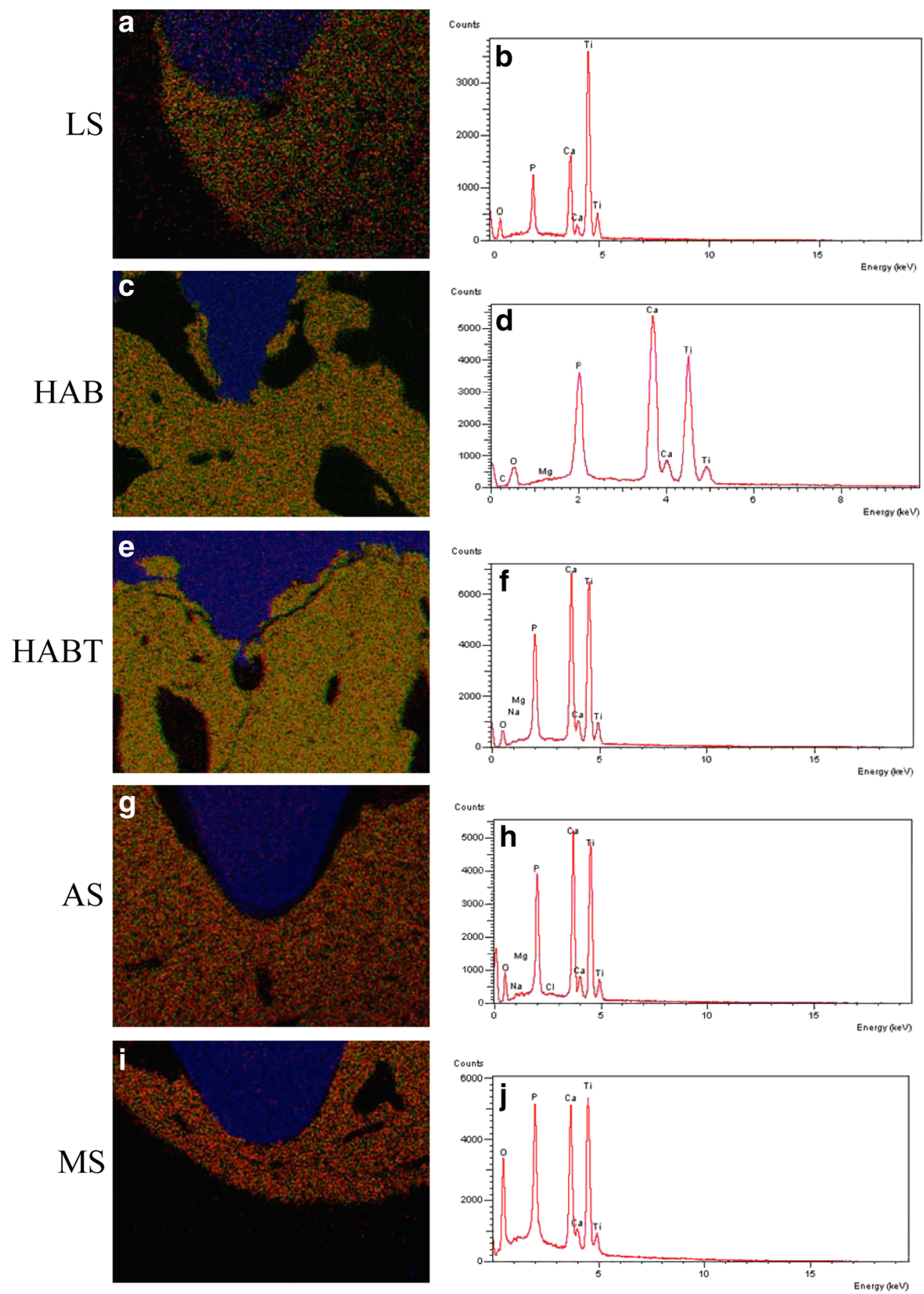

physiology, the pathogenesis of diseases, the action of drugs, the effects of surgical interventions, or testing of orthopedic and dental implants prior to clinical use in humans [77-79]. Indeed, they must have an appropriate accuracy by means of prior evidence and by demonstration of the limitations on the reality that will be represented [78]. The main concern of animal models is related to the respect for the ethical barriers of non-primary experimental intervention in humans [80]. Therefore, the use of animal models in implant research is a necessary step prior to undergoing clinical trials with new implant therapies. In the present study, rabbits were selected as the experimental model because they are easy to handle, due to low maintenance care, and because it is the smallest animal that can accept commercially available dental implants in long bones allowing the installation of conventional implants in the proximal region of the tibia, far from the growth plate (tibial metaphysis). However, experimental rabbit models posses some limitations compared to the humans, such as (1) faster skeletal maturity, (2) faster skeletal change, and (3) bone turnover. 
An interesting caveat in our study should be mentioned: Rabbits have skeletal changes faster than humans, in which they achieve skeletal maturity (closure o epiphyseal plates) shortly after reaching complete sexual development, at 6 months of age [81]. In this study, we have used rabbits with 5 months of age. This means that they do not exhibit complete skeletal maturity. Besides, the total elapsed time to resorb and redeposit bone in the rabbit tibia is about 6 weeks, and this characteristic represents a limitation of our initial period evaluated (30 days).

Finally, the elemental mapping analysis was employed to evaluate the distribution and homogeneity of $\mathrm{Ca}$ and $\mathrm{P}$ using SEM-EDX coupled to an electronic device. When the images of $\mathrm{Ca}$ (green) and $\mathrm{P}$ (red) are superimposed in the element mapping, the bone color should be yellow because the quantity of $\mathrm{Ca}$ in bone is greater than $\mathrm{P}$. Our results showed that $\mathrm{HAB}$ and $\mathrm{HABT}$ were highlighted in yellow, and LS, AS, and MS in orange. These findings suggest that $\mathrm{HAB}$ and $\mathrm{HABT}$ surfaces presented homogeneity distribution of $\mathrm{Ca}$ and $\mathrm{P}$ in the implant surface compared to the other groups, although high peaks of $\mathrm{Ca}$ and $\mathrm{P}$ were observed in all the different surfaces studied.

\section{Conclusions}

In summary, using three different surface treatments, we demonstrate at histomorphometric level that BIC was statistically superior on the $\mathrm{LS}, \mathrm{HAB}$, and $\mathrm{HABT}$ compared with $\mathrm{AS}$ and $\mathrm{MS}$ at 30,60 , and 90 days. BAFO of HAB at 30 days was statistically superior to all the other groups. At 60 and 90 days, BAFO of LS, $\mathrm{HAB}$, and HABT was higher than the AS and MS. Accordingly, our data indicate that the modified surfaces LS, HAB, and HABT favored the interaction between bone and implant and increased bone formation. In addition, HAB showed higher biological behavior favoring the osseointegration process. Indeed, to the best of our knowledge, this is the first study with close observation to show that $\mathrm{LS}, \mathrm{HAB}$, and HABT improved bone-toimplant contact and bone formation around osseointegrated implants.

Acknowledgments We would like to thank the Conexao Sistemas de Protese for providing the implants used in this study.

We thank Dr. Anahi Herrera Aparecida for her help in the deposition of hydroxyapatite on the implant surfaces by biomimetic method.

We also thank Dr. Karin Ellen Sisti for her help in the experimental surgical procedures.

We are extremely grateful to State of Sao Paulo Research Foundation (FAPESP) for financial support that enabled this study (\#2008/01613-8).

Author's contribution All authors participated in the design, execution, and analyses of the studies. de Molon RS and Queiroz TP drafted the manuscript. All authors were involved in revising the paper critically for important intellectual content, and all authors approved the final version to be published. TPQ had full access to all of the data in the study and take responsibility for the integrity of the data and the accuracy of the data analysis.

\section{Compliance with ethical standards}

Conflict of interest Thallita Pereira Queiroz declares that she has no conflict of interest. Rafael Scaf de Molon declares that he has no conflict of interest. Francisley Ávila Souza declares that he has no conflict of interest. Rogério Margonar declares that he has no conflict of interest. Anahi Herrera Aparecida Thomazini declares that she has no conflict of interest. Antonio Carlos Guastaldi declares that he has no conflict of interest. Eduardo Hochuli Vieira declares that he has no conflict of interest.

Funding The work was supported by the State of São Paulo Research Foundation (FAPESP) \#2008/016138.

Ethical approval All applicable international, national, and/or institutional guidelines for the care and use of animals were followed. All procedures performed in studies involving animals were in accordance with the ethical standards of the institution or practice at which the studies were conducted.

Informed consent For this type of study, formal consent is not required.

\section{References}

1. Albrektsson T, Branemark PI, Hansson HA, Lindstrom J (1981) Osseointegrated titanium implants. Requirements for ensuring a long-lasting, direct bone-to-implant anchorage in man. Acta Orthop Scand 52:155-170

2. Zarb GA, Schmitt A (1991) Osseointegration and the edentulous predicament. The 10-year-old Toronto study. Br Dent J 170:439-444

3. Buser D, Broggini N, Wieland M, Schenk RK, Denzer AJ, Cochran DL, Hoffmann B, Lussi A, Steinemann SG (2004) Enhanced bone apposition to a chemically modified SLA titanium surface. J Dent Res 83:529-533

4. Cho SA, Jung SK (2003) A removal torque of the laser-treated titanium implants in rabbit tibia. Biomaterials 24:4859-4863

5. de Molon RS, Morais-Camilo JA, Verzola MH, Faeda RS, Pepato MT, Marcantonio E Jr (2013) Impact of diabetes mellitus and metabolic control on bone healing around osseointegrated implants: removal torque and histomorphometric analysis in rats. Clin Oral Implants Res 24:831-837

6. Ellingsen JE (1998) Surface configurations of dental implants. Periodontol 2000(17):36-46

7. Ellingsen JE, Thomsen P, Lyngstadaas SP (2006) Advances in dental implant materials and tissue regeneration. Periodontol 41:136-156

8. Grossi-Oliveira GA, Antunes AA, Elias CN, Wennerberg A, Sennerby L, Salata LA (2015) Early osseointegration events on Neoss(R) ProActive and bimodal implants: a comparison of different surfaces in an animal model. Clin Implant Dent Relat Res 17: 1060-1072

9. Abagnale G, Steger M, Nguyen VH, Hersch N, Sechi A, Joussen S, Denecke B, Merkel R, Hoffmann B, Dreser A, Schnakenberg U, Gillner A, Wagner W (2015) Surface topography enhances differentiation of mesenchymal stem cells towards osteogenic and adipogenic lineages. Biomaterials 61:316-326

10. Kulkarni M, Patil-Sen Y, Junkar I, Kulkarni CV, Lorenzetti M, Iglic A (2015) Wettability studies of topologically distinct titanium surfaces. Colloids Surf B Biointerfaces 129:47-53 
11. de Avila ED, Lima BP, Sekiya T, Torii Y, Ogawa T, Shi W, Lux R (2015) Effect of UV-photofunctionalization on oral bacterial attachment and biofilm formation to titanium implant material. Biomaterials 67:84-92

12. Souza FA, Queiroz TP, Sonoda CK, Okamoto R, Margonar R, Guastaldi AC, Nishioka RS, Garcia Junior IR (2014) Histometric analysis and topographic characterization of $\mathrm{cp} \mathrm{Ti}$ implants with surfaces modified by laser with and without silica deposition. J Biomed Mater Res B Appl Biomater 102:1677-1688

13. Albrektsson T, Wennerberg A (2004) Oral implant surfaces: part 1 -review focusing on topographic and chemical properties of different surfaces and in vivo responses to them. Int J Prosthodont 17: 536-543

14. Buser D, Mericske-Stern R, Bernard JP, Behneke A, Behneke N, Hirt HP, Belser UC, Lang NP (1997) Long-term evaluation of nonsubmerged ITI implants. Part 1: 8-year life table analysis of a prospective multi-center study with 2359 implants. Clin Oral Implants Res 8:161-172

15. Li LH, Kong YM, Kim HW, Kim YW, Kim HE, Heo SJ, Koak JY (2004) Improved biological performance of Ti implants due to surface modification by micro-arc oxidation. Biomaterials 25:2867-2875

16. Faeda RS, Tavares HS, Sartori R, Guastaldi AC, Marcantonio E Jr (2009) Biological performance of chemical hydroxyapatite coating associated with implant surface modification by laser beam: biomechanical study in rabbit tibias. J Oral Maxillofac Surg 67:1706-1715

17. Lin A, Wang CJ, Kelly J, Gubbi P, Nishimura I (2009) The role of titanium implant surface modification with hydroxyapatite nanoparticles in progressive early bone-implant fixation in vivo. Int $\mathbf{J}$ Oral Maxillofac Implants 24:808-816

18. Vercaigne S, Wolke JG, Naert I, Jansen JA (1998) Bone healing capacity of titanium plasma-sprayed and hydroxylapatite-coated oral implants. Clin Oral Implants Res 9:261-271

19. de Avila ED, de Molon RS, Spolidorio DMP, Mollo FD (2013) Implications of surface and bulk properties of abutment implants and their degradation in the health of periodontal tissue. Materials 6: 5951-5966

20. de Avila ED, de Molon RS, Vergani CE, Mollo FD, Salih V (2014) The relationship between biofilm and physical-chemical properties of implant abutment materials for successful dental implants. Materials 7:3651-3662

21. Hao L, Lawrence J (2007) Wettability modification and the subsequent manipulation of protein adsorption on a Ti6A14V alloy by means of CO2 laser surface treatment. J Mater Sci Mater Med 18: $807-817$

22. Norde W (1986) Adsorption of proteins from solution at the solid liquid interface. Adv Colloid Interf Sci 25:267-340

23. Gittens RA, Scheideler L, Rupp F, Hyzy SL, Geis-Gerstorfer J, Schwartz Z, Boyan BD (2014) A review on the wettability of dental implant surfaces II: biological and clinical aspects. Acta Biomater 10:2907-2918

24. de Avila ED, de Molon RS, Lima BP, Lux R, Shi W, Junior MJ, Spolidorio DM, Vergani CE, de Assis Mollo Junior F (2016) Impact of physical chemical characteristics of abutment implant surfaces on bacteria adhesion. J Oral Implantol 42:153-158

25. Picraux ST, Pope LE (1984) Tailored surface modification by ion implantation and laser treatment. Science 226:615-622

26. Gaggl A, Schultes G, Muller WD, Karcher H (2000) Scanning electron microscopical analysis of laser-treated titanium implant surfaces-a comparative study. Biomaterials 21:1067-1073

27. Park EK, Lee YE, Choi JY, Oh SH, Shin HI, Kim KH, Kim SY, Kim S (2004) Cellular biocompatibility and stimulatory effects of calcium metaphosphate on osteoblastic differentiation of human bone marrow-derived stromal cells. Biomaterials 25:3403-3411

28. Queiroz TP, Souza FA, Guastaldi AC, Margonar R, Garcia-Junior IR, Hochuli-Vieira E (2013) Commercially pure titanium implants with surfaces modified by laser beam with and without chemical deposition of apatite. Biomechanical and topographical analysis in rabbits. Clin Oral Implants Res 24:896-903

29. Sisti KE, de Rossi R, Antoniolli AM, Aydos RD, Guastaldi AC, Queiroz TP, Garcia IR Jr, Piattelli A, Tavares HS (2012) Surface and biomechanical study of titanium implants modified by laser with and without hydroxyapatite coating, in rabbits. J Oral Implantol 38:231-237

30. Sisti KE, Piattelli A, Guastaldi AC, Queiroz TP, de Rossi R (2013) Nondecalcified histologic study of bone response to titanium implants topographically modified by laser with and without hydroxyapatite coating. Int J Periodontics Restorative Dent 33:689-696

31. Daculsi G, Laboux O, Malard O, Weiss P (2003) Current state of the art of biphasic calcium phosphate bioceramics. J Mater Sci Mater Med 14:195-200

32. Davies JE (2003) Understanding peri-implant endosseous healing. J Dent Educ 67:932-949

33. Barrere F, van der Valk CM, Dalmeijer RA, Meijer G, van Blitterswijk CA, de Groot K, Layrolle P (2003) Osteogenecity of octacalcium phosphate coatings applied on porous metal implants. J Biomed Mater Res A 66:779-788

34. Barrere F, van der Valk CM, Dalmeijer RA, van Blitterswijk CA, de Groot K, Layrolle P (2003) In vitro and in vivo degradation of biomimetic octacalcium phosphate and carbonate apatite coatings on titanium implants. J Biomed Mater Res A 64:378-387

35. Barrere F, van der Valk CM, Meijer G, Dalmeijer RA, de Groot K, Layrolle P (2003) Osteointegration of biomimetic apatite coating applied onto dense and porous metal implants in femurs of goats. J Biomed Mater Res B Appl Biomater 67:655-665

36. Bourgeois B, Laboux O, Obadia L, Gauthier O, Betti E, Aguado E, Daculsi G, Bouler JM (2003) Calcium-deficient apatite: a first in vivo study concerning bone ingrowth. J Biomed Mater Res A 65:402-408

37. Junker R, Dimakis A, Thoneick M, Jansen JA (2009) Effects of implant surface coatings and composition on bone integration: a systematic review. Clin Oral Implants Res 20(Suppl 4):185-206

38. Strnad Z, Strnad J, Povysil C, Urban K (2000) Effect of plasmasprayed hydroxyapatite coating on the osteoconductivity of commercially pure titanium implants. Int J Oral Maxillofac Implants 15: 483-490

39. Vidigal GM Jr, Aragones LC, Campos A Jr, Groisman M (1999) Histomorphometric analyses of hydroxyapatite-coated and uncoated titanium dental implants in rabbit cortical bone. Implant Dent 8: 295-302

40. Palka V, Postrkova E, Koerten HK (1998) Some characteristics of hydroxylapatite powder particles after plasma spraying. Biomaterials 19:1763-1772

41. Aparecida AH, Fook MV, Guastaldi AC (2009) Biomimetic apatite formation on ultra-high molecular weight polyethylene (UHMWPE) using modified biomimetic solution. J Mater Sci Mater Med 20:1215-1222

42. Forsgren J, Svahn F, Jarmar T, Engqvist H (2007) Formation and adhesion of biomimetic hydroxyapatite deposited on titanium substrates. Acta Biomater 3:980-984

43. Oyane A, Onuma K, Ito A, Kim HM, Kokubo T, Nakamura T (2003) Formation and growth of clusters in conventional and new kinds of simulated body fluids. J Biomed Mater Res A 64:339-348

44. Wang X, Li Y, Lin J, Hodgson PD, Wen C (2008) Effect of heattreatment atmosphere on the bond strength of apatite layer on $\mathrm{Ti}$ substrate. Dent Mater 24:1549-1555

45. Moritz N, Jokinen M, Peltola T, Areva S, Yli-Urpo A (2003) Local induction of calcium phosphate formation on $\mathrm{TiO} 2$ coatings on titanium via surface treatment with a $\mathrm{CO} 2$ laser. J Biomed Mater Res A 65:9-16

46. Palmquist A, Emanuelsson L, Branemark R, Thomsen P (2011) Biomechanical, histological and ultrastructural analyses of laser 
micro- and nano-structured titanium implant after 6 months in rabbit. J Biomed Mater Res B Appl Biomater 97:289-298

47. Souza FA, Queiroz TP, Guastaldi AC, Garcia-Junior IR, MagroFilho O, Nishioka RS, Sisti KE, Sonoda CK (2013) Comparative in vivo study of commercially pure Ti implants with surfaces modified by laser with and without silicate deposition: biomechanical and scanning electron microscopy analysis. J Biomed Mater Res B Appl Biomater 101:76-84

48. Gandolfi MG, Taddei P, Siboni F, Perrotti V, Iezzi G, Piattelli A, Prati C (2015) Micro-topography and reactivity of implant surfaces: an in vitro study in simulated body fluid (SBF). Microsc Microanal 21:190-203

49. Kilkenny C, Browne WJ, Cuthill IC, Emerson M, Altman DG (2012) Improving bioscience research reporting: the ARRIVE guidelines for reporting animal research. Osteoarthr Cartil 20: 256-260

50. Giro G, Coelho PG, Pereira RM, Jorgetti V, Marcantonio E Jr, Orrico SR (2011) The effect of oestrogen and alendronate therapies on postmenopausal bone loss around osseointegrated titanium implants. Clin Oral Implants Res 22:259-264

51. Zagury R, Harari ND, Conz MB, Soares Gde A, Vidigal GM Jr (2007) Histomorphometric analyses of bone interface with titanium-aluminum-vanadium and hydroxyapatite-coated implants by biomimetic process. Implant Dent 16:290-296

52. Albrektsson T (2008) Hard tissue implant interface. Aust Dent J 53(Suppl 1):S34-S38

53. Albrektsson T, Wennerberg A (2004) Oral implant surfaces: part 2review focusing on clinical knowledge of different surfaces. Int $\mathrm{J}$ Prosthodont 17:544-564

54. Amoroso PF, Adams RJ, Waters MG, Williams DW (2006) Titanium surface modification and its effect on the adherence of Porphyromonas gingivalis: an in vitro study. Clin Oral Implants Res 17:633-637

55. Berglundh T, Persson L, Klinge B (2002) A systematic review of the incidence of biological and technical complications in implant dentistry reported in prospective longitudinal studies of at least 5 years. J Clin Periodontol 29(Suppl 3):197-212 discussion 232-193

56. Mombelli A (2002) Microbiology and antimicrobial therapy of peri-implantitis. Periodontol 2000(28):177-189

57. Mombelli A, Muller N, Cionca N (2012) The epidemiology of periimplantitis. Clin Oral Implants Res 23(Suppl 6):67-76

58. Norowski PA Jr, Bumgardner JD (2009) Biomaterial and antibiotic strategies for peri-implantitis: a review. J Biomed Mater Res B Appl Biomater 88:530-543

59. Quirynen M, De Soete M, van Steenberghe D (2002) Infectious risks for oral implants: a review of the literature. Clin Oral Implants Res 13:1-19

60. Quirynen M, De Soete M, van Steenberghe D (1999) Intra-oral plaque formation on artificial surfaces. In: Lang NP, Karring T, Lindhe J (eds) Book title. Quintessence Books, Berlin

61. Bollen CM, Lambrechts P, Quirynen M (1997) Comparison of surface roughness of oral hard materials to the threshold surface roughness for bacterial plaque retention: a review of the literature. Dent Mater 13:258-269

62. Iezzi G, Scarano A, Petrone G, Piattelli A (2007) Two human hydroxyapatite-coated dental implants retrieved after a 14-year loading period: a histologic and histomorphometric case report. J Periodontol 78:940-947

63. Caulier H, van der Waerden JP, Wolke JG, Kalk W, Naert I, Jansen JA (1997) A histological and histomorphometrical evaluation of the application of screw-designed calciumphosphate (Ca-P)-coated implants in the cancellous maxillary bone of the goat. J Biomed Mater Res 35:19-30

64. Soballe K (1993) Hydroxyapatite ceramic coating for bone implant fixation. Mechanical and histological studies in dogs. Acta Orthop Scand Suppl 255:1-58

65. Xuereb M, Camilleri J, Attard NJ (2015) Systematic review of current dental implant coating materials and novel coating techniques. Int J Prosthodont 28:51-59

66. Guo L, Li H (2004) Fabrication and characterization of thin nanohydroxyapatite coatings on titanium. Surf Coat Technol 185:268-274

67. Barrere F, Layrolle P, Van Blitterswijk CA, De Groot K (2001) Biomimetic coatings on titanium: a crystal growth study of octacalcium phosphate. J Mater Sci Mater Med 12:529-534

68. Freire AR, Rossi AC, Queiroz TP, Gulinelli JL, Souza FA, Margonar R, Garcia-Junior IR, Hochuli-Vieira E, Okamoto R (2012) Histometric analysis of bone repair in bone-implant interface using a polylactic/polyglycolic acid copolymer associated with implants in rabbit tibia. J Oral Implantol 38 Spec No:449-457

69. Kim HW, Koh YH, Li LH, Lee S, Kim HE (2004) Hydroxyapatite coating on titanium substrate with titania buffer layer processed by sol-gel method. Biomaterials 25:2533-2538

70. McGlumphy EA, Peterson LJ, Larsen PE, Jeffcoat MK (2003) Prospective study of 429 hydroxyapatite-coated cylindric omniloc implants placed in 121 patients. Int J Oral Maxillofac Implants 18:82-92

71. Wennerberg A, Albrektsson T (2009) Effects of titanium surface topography on bone integration: a systematic review. Clin Oral Implants Res 20(Suppl 4):172-184

72. Cooper LF (2000) A role for surface topography in creating and maintaining bone at titanium endosseous implants. J Prosthet Dent $84: 522-534$

73. Le Guehennec L, Soueidan A, Layrolle P, Amouriq Y (2007) Surface treatments of titanium dental implants for rapid osseointegration. Dent Mater 23:844-854

74. Meirelles L, Arvidsson A, Andersson M, Kjellin P, Albrektsson T, Wennerberg A (2008) Nano hydroxyapatite structures influence early bone formation. J Biomed Mater Res A 87:299-307

75. Nayar S, Sinha MK, Basu D, Sinha A (2006) Synthesis and sintering of biomimetic hydroxyapatite nanoparticles for biomedical applications. J Mater Sci Mater Med 17:1063-1068

76. Zhang Q, Chen J, Feng J, Cao Y, Deng C, Zhang X (2003) Dissolution and mineralization behaviors of HA coatings. Biomaterials 24:4741-4748

77. de Molon RS, de Avila ED, Boas Nogueira AV, Chaves de Souza JA, Avila-Campos MJ, de Andrade CR, Cirelli JA (2014) Evaluation of the host response in various models of induced periodontal disease in mice. J Periodontol 85:465-477

78. de Molon RS, de Avila ED, Cirelli JA (2013) Host responses induced by different animal models of periodontal disease: a literature review. J Investig Clin Dent 4:211-218

79. Mapara M, Thomas BS, Bhat KM (2012) Rabbit as an animal model for experimental research. Dent Res J (Isfahan) 9:111-118

80. de Molon RS, Mascarenhas VI, de Avila ED, Finoti LS, Toffoli GB, Spolidorio DM, Scarel-Caminaga RM, Tetradis S, Cirelli JA (2016) Long-term evaluation of oral gavage with periodontopathogens or ligature induction of experimental periodontal disease in mice. Clin Oral Investig 20:1203-1216

81. Gilsanz V, Roe TF, Gibbens DT, Schulz EE, Carlson ME, Gonzalez O, Boechat MI (1988) Effect of sex steroids on peak bone density of growing rabbits. Am J Phys 255:E416-E421 